\title{
Pelo tear da ficção: cenas de autoritarismo em Moçambique e Timor Leste
}

\author{
Claudiany Pereira*
}

\begin{abstract}
Resumo: Imagens de autoritarismo não faltam na ficção contemporânea em língua portuguesa. Após vivenciarem os efeitos histórico-sociais ocasionados por 42 anos de Regime de Exceção Democrática, os escritores portugueses, africanos lusófonos e timorenses não cessam em exorcizar esse fantasma através da escrita. Em cada um destes locais de cultura o autoritarismo se configurou de forma distinta. E as imagens mostradas na ficção contemporânea são uma faceta (ou várias facetas) desse "jogo a duas mãos que é a fabricação do medo". Neste trabalho destacaremos cenas de autoritarismo veiculadas na ficção moçambicana e timorense, através da obra dos escritores Mia Couto e Luís Cardoso.
\end{abstract}

Palavras-chave: Literatura de Timor Leste; Literatura Pós-Colonial; Regimes ditatoriais; África Lusófona

\begin{abstract}
Images of authoritarianism do not lack in the contemporary fiction in portuguese language. After live the historical-social effects caused by 42 years of regimen of democratic exception, the portuguese, lusophonics african and timorenses writers do not cease in exorcising that ghost through the writing. In each one of these culture places the authoritarianism was configured in a different ways. And the images shown in the contemporary fiction are a facet (or several facets) of that "game to two hands that is the production of the fear". In this work we will detach scenes of authoritarianism transmitted in the mozambican and east timorese fiction, through the writers work Mia Couto and Luís Cardoso.
\end{abstract}

Keywords: East Timor Literature; Post-Colonial Literature; Dictatorial government; Lusophonic Africa
O torturador necessita da vítima
Para criar verdade nesse jogo a duas mãos
Que é a fabricação do medo.

Mia Couto

Imagens de autoritarismo não faltam na ficção contemporânea em língua portuguesa. Após vivenciarem os efeitos histórico-sociais ocasionados por 42 anos de Regime de Exceção Democrática, os escritores portugueses, africanos lusófonos e timorenses não cessam em exorcizar esse fantasma através da escrita. Em cada um destes locais de cultura o

\footnotetext{
" Claudiany Pereira é doutoranda em Teoria da Literatura na PUCRS e Bolsista - Pesquisadora do CNPq. Seus estudos são direcionados às literaturas lusófonas, com ênfase nas literaturas africanas e timorense. Sua mais recente publicação é "A travessia literária de Timor Leste: Literatura Fundacional e reconstrução da História às margens da Lusofonia. In: BARBOSA, Márcia Helena Saldanha (Org.). Questões de intertextualidade. Passo Fundo: UPF, 2005.
} 
autoritarismo se configurou de forma distinta. E as imagens mostradas na ficção contemporânea são uma faceta (ou várias facetas) desse "jogo a duas mãos que é a fabricação do medo".

Esse tema passou a despertar meu interesse, a partir das histórias relatadas por excombatentes da guerra colonial e pelos Capitães de Abril, por experienciar os efeitos que até hoje direcionam a vida dos portugueses e por entrar em contato com documentos resgatados pelo Centro de Documentação 25 de Abril da Universidade de Coimbra sobre a participação dos soldados portugueses na Guerra Colonial. Estar em Portugal é vivenciar a personificação da história que culminou com a Revolução dos Cravos, arquitetada e decretada pelos Capitães de Abril, em 25 de Abril de 1974.

Em Portugal os sentidos da Revolução se concretizam a partir da derrocada de quase meio século de Ditadura - entendida também como regime de governo em que todas as liberdades, incluindo as individuais, passaram por um processo rigoroso de censura - fato este que constitui o pilar da crise de identidade discutida até hoje pela ficção portuguesa. Rompem-se os laços com essa prática de exceção democrática, mas o país não se encontra, nesse momento histórico, alicerçado em um projeto sólido de reconstrução política, uma vez que, por muito tempo, o passado de glórias, aliado aos recursos econômicos oriundos das colônias, impulsionou seu fazer histórico. Se, no país-sede da CPLP ${ }^{1}$, a cessação do poder Salazarista corporifica a liberdade de ação, nas colônias, essa passagem histórica - essa linha limítrofe entre duas independências - é o sinal verde para o início de uma outra batalha, delimitadora dos destinos das novas futuras nações africanas de língua portuguesa. Em Moçambique o 25 de Abril corresponde ao 25 de Junho, quando a FRELIMO (Frente de Libertação para Moçambique) chega ao poder. Em Timor Leste corresponde ao 28 de Novembro de 1975 e, após a ocupação Indonésia no mesmo ano, ao 20 de Maio de 2002, data da sua efetiva independência. Estas datas, no entanto, num primeiro momento, foram tão passageiras quanto a utopia dos sentidos da Revolução. Quando os portugueses se retiraram do território timorense, os indonésios instauraram novo regime ditatorial que, em temos de perdas humanas, foi considerado mais arrasador que o primeiro, tanto que Portugal se torna parceiro de Timor Leste no movimento pela desocupação Indonésia. Em Moçambique, quando se dá a conquista da independência com relação à metrópole, insurge-se outra

\footnotetext{
${ }^{1}$ Sigla da Comunidade dos Países de Língua Portuguesa. Este grupo foi institucionalizado em 1996, e tem como membros todos os países onde a língua portuguesa é oficial: Angola, Brasil, Cabo Verde, Guiné-Bissau, Moçambique, Portugal, São Tomé e Príncipe e Timor Leste.
} 
guerrilha interna de partidos políticos (e etnias) distintas pelo poder; em outras palavras, tem início a Guerra Civil.

Se, por um lado, o Governo Salazarista conclama os soldados portugueses a combaterem na África pela manutenção do regime, por outro, dissemina o racismo contra os 'pretos bárbaros' das colônias. É sabido que um regime autoritarista como o impingido por António Oliveira Salazar subsiste através da criação e da manutenção de um imaginário específico que o sustenta. Com relação à guerra colonial, nas 'províncias ultramarinas', estas narrativas formavam a imagem de que os africanos guerrilheiros eram agentes subversivos, bandidos armados prontos a exterminar os soldados portugueses, a raça branca e a proclamada pátria considerada pelo regime "una e indivisível do Minho ao Timor".

Duas mensagens de soldados portugueses desertores e/ou capturados pela FRELIMO comprovam essa prerrogativa de que a guerra se mantém através da tessitura de narrativas sustentadas e sustentáveis do regime. A mensagem de Fernando dos Santos Rosa, capturado ‘debaixo de fogo' pelos soldados da FRELIMO, em 11/11/1968, salienta:

Aqui na FRELIMO é tudo igual: não há diferença dos soldados para com os superiores. Não é como os piratas portugueses. Pois os soldados da FRELIMO não comem ninguém [grifo meu]; eles não estão a lutar contra o povo português, mas sim contra o Regime de Salazar, porque ele é fascista ${ }^{2}$.

O grifo foi pontuado especificamente sobre a afirmativa "eles não comem ninguém", porque parece a narrativa que se repete em governos fascistas, cujo objetivo é despertar o medo e a ojeriza da população para tudo o que é contrário a esse sistema. Esse depoimento surge não apenas como desmitificador de uma realidade criada, como também ratifica o preconceito difundido pelos governos ditatoriais. Os movimentos de esquerda, invariavelmente, eram considerados além de subversivos, instituições compostas por militantes que desenvolviam costumes bárbaros, componentes associados na medida exata para a instauração do medo na sociedade civil.

Outro depoimento do soldado Américo Neves de Souza, evadido do Quartel de Mueda, em 13/10/1968, observa:

Porque não fazes como eu que fui pela razão e vi que estes homens que andam a lutar, que não

é para matarem a raça branca [grifo meu], mas sim querem que o governo português lhes dê o que lhes pertence, querem a liberdade, querem a sua independência porque desde que estas províncias têm estado debaixo do domínio português à população de raça negra tem sido tratada como escrava e por isso é que eles querem a liberdade ${ }^{3}$.

\footnotetext{
${ }^{2}$ Este excerto foi retirado de um documento da FRELIMO, que tem por título "Independência ou morte, venceremos!", coletado no Centro de Documentação 25 de Abril, da Universidade de Coimbra. A data que consta no documento é 11/11/1968.

${ }^{3}$ Excerto retirado do documento citado na Nota 2.
} 
Esta fonte documental de onde foram extraídos os excertos acima se intitula "Independência ou Morte, venceremos!" e compõe-se de duas partes: a primeira é um chamamento feito pela FRELIMO aos soldados portugueses, esclarecendo as causas da guerrilha e conclamando-os para a luta; a segunda apresenta declarações que os soldados desertores e capturados prestaram e que foram redirecionados, via transmissão radiofônica, aos colegas em exercício na tropa colonial.

Gláucia Gonçalves lembra, em "Pós-Colonialismo, Império e Globalização: dois pratos da balança" (2002), que se o colonialismo é cotidiano na nossa sociedade e nos nossos discursos: "vejamos nele um assombrar feliz, necessário, esclarecedor, que faz com que o retorno do colonialismo passe a ser um trabalho de memória não do que foi esquecido, mas daquilo que não se quer esquecer" ${ }^{4}$.

Nesse sentido, passados mais de trinta anos das guerras coloniais na África, avultam no mercado editorial português as obras que dão conta da memória desta guerra. Surgem nesse momento, ouso arriscar, por dois motivos específicos: primeiro porque já há o distanciamento necessário para voltar aos olhos a esse passado com a isenção e a compreensão necessárias, segundo porque pelo desfiar da memória, os ex-combatentes podem exorcizar esse 'fantasma' de terem-se, por obra de um regime, tornado 'assassinos'. João de Melo, no capítulo de abertura de Autópsia de um mar de ruínas, descreve a impressão de um jovem soldado atemorizado no campo de batalha, o que ele vê e abate não é "um corpo em sua concreta forma definida, mas a breve sombra de um vulto, sem corpo e sem cabeça - ou com ela estranhamente suspensa e degolada, que é como todas as sombras se movem nas noites furtivas da guerra" ${ }^{\prime}$. Essa cena retrata a mentalidade de um soldado que é instruído a matar para não morrer. E a convicção da autodefesa imposta, de que é preciso exterminar o inimigo público, é produzida, transmitida e difundida através das elaborações discursivas arquitetadas pelos regimes fascistas.

O autoritarismo se manifesta de variadas formas, no âmbito histórico-cultural, através da imposição de uma língua sobre as demais, ou mesmo pela difusão de idéias contraditórias ou inverossímeis; no âmbito humano-social, pela violação física do ser humano, desde o cerceamento das liberdades até à tortura e à morte. A ficção contemporânea lusófona, sobretudo a literatura dos países africanos de língua portuguesa e de Timor Leste, aponta e

\footnotetext{
${ }^{4}$ Gonçalves, Gláucia Renate. Pós-Colonialismo, Império e Globalização: dois pratos da balança. Revista Aletria. Revista de Estudos de Literatura. N 9. 2000. UFMG. comentário atribuído a Ilse Vieira, p. 138.

${ }^{5}$ MELO, João de. Autópsia de um mar de ruínas. Lisboa: Dom Quixote, 1997.
} 
denuncia essa prática. O inimigo comum, no entanto, não é Portugal ou os portugueses, e sim o regime fascista, nesse caso, personificado por Salazar.

Diz o escritor moçambicano Mia Couto que a literatura 'se calhar' ajuda na reconstituição da memória coletiva, na recuperação do passado e na discussão sobre a realidade social. E é mesmo essa linha de interpretação do texto literário que se torna pertinente à análise que damos prosseguimento nesse trabalho. Dois locais de cultura específicos integram meu horizonte de expectativa que são Moçambique e Timor Leste.

\section{II}

Vinte e Zinco é o antepenúltimo romance publicado de Mia Couto, lançado em Abril de 1999, data que marca a comemoração dos 25 anos do aniversário da Revolução dos Cravos em Portugal. A Editorial Caminho organizou uma coletânea de textos de 11 escritores lusófonos motivada por essa rememoração dos sentidos da revolução para Portugal e suas colônias. Dentre os autores estão Mia Couto, Almeida Faria, Urbano Tavares Rodrigues, Maria Isabel Barreno e Germano de Almeida. O texto tem uma epígrafe, à moda de Mia, que pode ser entendida como uma referência à independência das colônias africanas lusófonas, que não se enquadram nos mesmos moldes da abertura política experimentada pela metrópole. Os significados da revolução mostram-se distintos para os dois locais — um de onde se fala, e outro sobre o qual se fala: "Vinte e cinco é para vocês que vivem nos bairros de cimento. Para nós, negros pobres que vivemos na madeira e zinco, o nosso dia ainda está por vir”.

Pela visão de um humanista sobre a totalidade das facções integrantes da diáspora portuguesa, nessa ação de conquista que orientou o imaginário português até a década de 70, podemos perceber como o ‘jogo a duas mãos que é a fabricação do medo’ envolve algozes e vítimas, poder e submissão, Portugal e África. Em várias cenas de outras narrativas, Mia Couto enfatiza o estranhamento que os portugueses sentem com relação à cultura africana. Nessa obra específica, destaca o sofrimento do degredo, de estar longe da pátria a custa da defesa de um regime que não se ocupa das vidas daqueles que o sustentam. Esse fato contribuiu para acirrar o descontentamento que impulsionou a queda da Ditadura em Portugal. Até mesmo os capitães, deslocados para as colônias para defender a Pátria portuguesa, deramse conta do abandono a que estavam sujeitos tanto nas frentes de batalha, quanto na administração do sistema público de governo.

Os diferentes pontos de vista, que permeiam a narrativa, permitem que conheçamos as perspectivas e as motivações de personagens que integram uma ou outra facção histórica, pois 
na visão de um, o outro é sempre o seu contrário. Isso faz com que tenhamos noção da complexidade da questão colonial. A cronologia a que a obra remete pertence à história, principia em 19/4 e vai até 30/4 do ano de 1974. Esse recorte temporal só tem sentido porque antecede e procede a um fato político que é a Revolução dos Cravos. Mia Couto escreve um diário, que é algo íntimo e pessoal, para falar de um problema que é coletivo, embora também pessoal, pois começa no âmbito particular e estende-se à coletividade, à idéia de nação e de cultura. $\mathrm{O}$ autor tece um diário para Moçambique, e como a nação é também a soma das suas particularidades, esse diário circunda a micro-histórias dos indivíduos que a compõe, pois a escrita que ali se encontra é a da coletividade. Assim, o 25 de Abril expande-se dos limites portugueses, enquadrando-se na noção de Benedict Anderson ${ }^{6}$ de comunidade imaginada, que é aquela que coexiste para além das fronteiras delimitadas de um dado país.

A narrativa se aproxima dos conceitos de diário estabelecidos por Phillipe Lejeune ${ }^{7}$ e Georges Gusdorf ${ }^{8}$, à medida que busca uma verdade, adentra o território da identidade, apresenta seqüência temporal, é a expressão do 'eu' (aqui o sujeito é a coletividade) e elege um fato a ser contado. O autor/narrador conhece o desfecho destes episódios que são históricos e deles possui o testemunho e o distanciamento necessários à elaboração deste gênero. Afasta-se, entretanto, dessa mesma compreensão por não ser a expressão de um eusujeito histórico, não tratar de uma realidade imediata vivenciada pelo autor, não falar sobre o instante presente do protagonista. Essa memória que será desfiada através do diário, diz Mia Couto, está guardada com muito cuidado, "com o cuidado de quem sabe que não vale a pena ajustar as contas".

As cenas de autoritarismo que figuram na obra estendem-se do viver africano ao braço do poder colonial, na figura de Lourenço de Castro, funcionário da PIDE - a Polícia Política Portuguesa -, em exercício em Moçambique. Interessante observar, na composição desta personagem, é que ao desempenhar seu papel de oficial da bandeira portuguesa, representa-a por convicção e também por ódio que tem ao solo africano, aos pretos que causaram a morte de seu pai. Estes elementos são tão fortemente trabalhados por Mia Couto que, mesmo sabendo que Lourenço de Castro é a personificação do fascismo português, não deixamos de experimentar a visão da Guerra Colonial, pelo viés daqueles que saíram de sua terra para defender interesses econômicos em nome de uma causa nacional (colonial imperialista). Em

\footnotetext{
${ }^{6}$ ANDERSON, Benedict. Nação e consciência nacional. São Paulo: Ática, 1989.

${ }^{7}$ LEJEUNE, Phillipe. Le pacte autobiographique. Paris: Seuil, 1975

${ }^{8}$ GUSDORF, Georges. Les écritures du moi. Paris: Odile Jacob, 1991.
} 
solo estrangeiro, adaptaram-se a uma nova realidade, em que o desenraizamento a que foram submetidos os leva a integrar o espaço imaginário de entre-lugar ${ }^{9}$, pois estar no local de acolhimento não significa necessariamente estar identificado com ele.

Lourenço, cuja relação com a PIDE foi herdada do pai Joaquim de Castro, resumia seu ofício a prender e torturar 'negros subversivos', 'traidores do regime'. "Sua ascensão na política se fez rápida, à força de muito serviço mostrado. E de muito mais serviço que não podia mostrar" (p. 27). As ficções trazem à tona, pelo (des)compromisso com a história, narrativas de torturas que hoje conhecemos através de testemunhos e relatos de presos políticos, torturados pelos regimes. O primeiro episódio narrado trata do suicídio coletivo dos negros: Joaquim de Castro obrigava os presos a saltarem do avião em mar aberto. Num destes saltos os presos se unem e levam consigo o algoz, que acaba experimentando a própria artimanha. Essa cena se passa na infância da personagem, e ele, não apenas a presencia, como o pavor da experiência o torna impotente para prestar socorro ao pai. Essa lembrança atormenta o policial na vida adulta. Na sala de tortura da cadeia de Moebase, chamada Kula, Lourenço exorcizava seus fantasmas castigando os presos. Esta sala, na época de seu pai, era constantemente pintada de branco para disfarçar as marcas de sangue deixadas. Os métodos utilizados, resgatados pela mediação ficcional, eram para além de espancamentos e torturas, que incluíam mutilações do corpo, abusos sexuais.

Nos antecedentes do 25 de Abril a prisão, que é cenário constante neste diário, estava lotada de presos subversivos, isto é, daqueles contrários ao regime imperialista de Salazar. Desta prisão fugiam homens para engrossar a guerrilha no mato. Nas colônias, quando é deflagrada a queda do regime, esse fato histórico adquire um significado distinto. Mia Couto e Luís Cardoso - o primeiro romancista de Timor Leste - destacam uma faceta desse episódio: o regime na metrópole quedou, mas seus representantes nas então províncias ultramarinas ficaram entregues à própria sorte. Ou seja, todos aqueles que defenderam uma causa, que dizia respeito à nação, ao sentimento imperialista português, tiveram que se defender por conta própria quando esse regime ruiu. Os dois autores trazem para a ficção esse momento, como sendo aquele em que foi comunicado à nação, indistintamente, por telefone e via rádio, que "caiu o regime em Lisboa". Há uma cena em que a personagem Lourenço de Castro surpreende-se com isso e pergunta que regime é esse que ruiu, pois para ele existia a una e indivisível pátria portuguesa, e o grande pai, que era Salazar.

\footnotetext{
${ }^{9}$ Noção estabelecida por BHABHA, Homi. O local da cultura. Belo Horizonte: UFMG, 1998.
} 
Se Vinte e zinco trata da fabricação do medo, visto como uma moeda de dupla face, é porque há a coroa portuguesa, conferindo poderes aos seus colonos administradores, médicos e policiais (Polícia Política), e há a formação da guerrilha, a política considerada subversiva Pró-Independência. De um lado está o Regime Salazarista, de outro a mão da FRELIMO a resistir ao colonialismo. Irene, a personagem portuguesa aculturada, fazia a ponte entre estes dois mundos, cambiando documentos oficiais para a oposição.

Uma grande metáfora talhada por Mia Couto é a representação de Moçambique através da figura de Andaré Tchuvisco. O autor compõe uma personagem que é cegada por presenciar cenas de abusos cometidos pelo poder Salazarista. Na obra, surge a suspeita de que esta personagem seja o elo de ligação entre os presos que fugiam para reforçar a guerrilha nos matos, pois, para ultrapassar as fronteiras da prisão, precisavam da ajuda de uma pessoa idônea. O que reforça a imagem de que o cego Andaré pode ser lido como metáfora de Moçambique é o argumento apresentado por outra personagem, uma adivinha que vaticina a retomada da visão quando chegar o outro 25 , o que efetiva a libertação moçambicana.

Com relação à personagem cega, sua primeira aparição se dá ao passar das primeiras cenas, e é descrita como aquela que derruba a bandeira portuguesa às escondidas. A metáfora da cegueira não é nenhuma novidade na ficção contemporânea. O cego é aquele a quem é vedado o sentido da visão e é também aquele que é conduzido por mão alheia. Esta segunda alternativa nos parece a mais próxima da representação de Moçambique, nação 'guiada' pela mão do governo fascista até conquistar a autodeterminação.

Seguindo a linha dos flashes de autoritarismo apresentados na ficção, a personagem Joaquim de Castro, em um dado momento, precisa matar um preso que presenciou atos abusivos, mas não o pode fazer porque o mesmo era conhecido nas missões católicas: “os padres já não andavam de muita satisfeição com os maus tratos cometidos pela polícia colonial" (p.113). Em contrapartida, os mesmos padres expulsavam alunos da missão porque achavam que ali dentro se formavam os quadros nacionalistas. Historicamente é sabido que os quadros nacionalistas não apenas se formavam nas missões, como delas recebiam apoio incondicional. Muitos dos dirigentes da FRELIMO e MPLA (Movimento Popular para a Libertação de Angola) receberam bolsas de auxílio das missões metodistas. Aliás, a instituição metodista mais do que a católica foi responsável pela formação política das frentes independentistas nas ex-colônias africanas lusófonas.

$\mathrm{Na}$ esteira da questão nacionalista africana, Mia Couto compõe a personagem Marcelino, namorado de Irene - a portuguesa que se rende à causa pró-independência. Marcelino é torturado e morto na prisão de Moebase. O motivo aparente desse 
encarceramento é a ação praticada por seu grupo vinculado à imprensa subversiva. Irene escreve um diário, dentro do diário maior que é o de Moçambique, e registra através da poesia, que é o gênero literário representante da tradição literária moçambicana, sua angústia diante da morte de Marcelino. O poema é este:

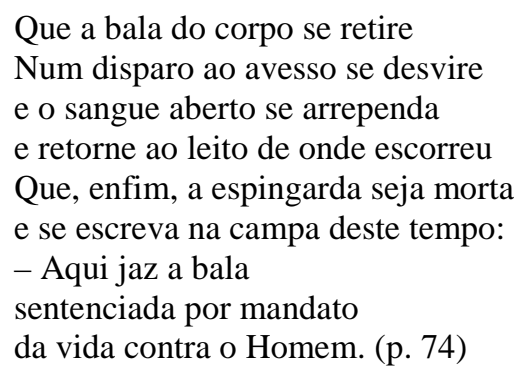

Além de referir à insanidade da guerra, a personagem refere à perda de um amor africano. Ela, uma portuguesa, apaixonou-se por um homem da terra: dois opostos que, nesse momento histórico, unem-se e se separam pelo mesmo motivo. Segundo Dona Margarida, o namorado quase-preto da irmã, "veio das tropas coloniais contaminado dessa doença - sonhar com futuros e liberdades" (p.74). Essa 'doença' ocorre num contexto em que os demais estados europeus estabeleciam com suas ex-colônias novas relações (neocolonialismo), e Portugal esforçava-se por manter os antigos vínculos imperiais, a custa da repressão dos movimentos nacionalistas.

As guerras na África podem ser consideradas como uma via possível de chamar atenção para a questão nacional, mesmo que os movimentos independentistas tenham sido duramente reprimidos pelo governo fascista. Ocorre que os saldos de uma guerra, as perdas humanas e econômicas são irreparáveis. Em contrapartida, se é possível citar um fator positivo em meio aos conflitos bélicos, pode-se dizer que, por um objetivo comum, estabeleceu-se um elo unificador de diferentes etnias. Angola, cujo exército nacional aceitou jovens militantes de diferentes etnias, para abraçarem a causa nacionalista, pode ser citada como exemplo. Etnias estas que, finda a guerra colonial, colocaram-se em facções opostas na disputa pelo poder nacional (MPLA X UNITA - União Nacional para a Independência Total de Angola). Segundo Joseph Ki-Zerbo, a violência das guerras, às vezes, é a única solução possível. Em depoimento ao $1^{\circ}$ Fórum Social Mundial, sediado em Porto Alegre, em 1998, um líder guerrilheiro das FARC's colombianas confirmou esse discurso, ao ser perguntado sobre a necessidade dos conflitos colombianos: se no Brasil há possibilidade de diálogo, façase o diálogo - respondeu -, na Colômbia, ele não é possível, por isso a necessidade e a justificação das guerrilhas. 
As formas de autoritarismo apresentadas na narrativa timorense principiam com a miscigenação lingüística e se direcionam aos excessos cometidos pelo poder colonial. Pelo desfiar da memória do narrador, o autor Luís Cardoso confirma que conta a história recente da nova nação, e que esta é também a sua história. Para isso, volta os olhos ao passado histórico e pessoal, que denomina como sendo os 'tempos de encantamento', quando acompanhava, itinerante por Timor, o ofício do pai enfermeiro. Esse tempo é também o da colonização portuguesa, quando nas escolas aprendia-se a sonhar com a Pátria Portuguesa que, apesar de distante, era minuciosamente estudada, desde os grandes vultos literários até o itinerário dos caminhos de ferro. Sobre esse assunto, Dalila Cabrita Mateus (1999) destaca que, nas colônias, os estudantes 'assimilados' conheciam a fundo as rotas dos caminhos-de-ferro, mesmo sem saberem ao certo o que era um comboio. Ou seja, nas escolas durante o período fascista, sobrepunha-se o estudo da cultura e da literatura portuguesas em detrimento das línguas, cultura e literaturas locais. Entre a escolha da língua falada por um grupo lingüístico minoritário e a língua da antiga potência colonizadora, o voto recaiu sobre esta última por ela ser a língua da unidade que, não representando nenhuma etnia distinta, tem a vantagem de, nesse aspecto, ser imparcial.

A crônica de Timor perpassa a história colonial, entendida pelo narrador também como o tempo do encantamento de sonhar com a pátria de Camões e Pessoa. O livro, que principia e culmina com a perda de memória do pai deste narrador, é narrativa do desfiar de uma memória: a da vida privada, quando pai e filho andavam itinerantes por Timor, paralelamente à memória do processo histórico que culminou com a independência da jovem nação - do colonialismo português à invasão Indonésia. Resgatam-se assim as travessias humana e histórica, particular e coletiva do povo maubere, do tempo em que um exseminarista de Dare, Alexandre Gusmão, era guarda-redes da acadêmica e criava frangos na baliza, até o momento em que Alexandre Xanana Gusmão se torna o comandante da guerrilha e "incendiava os corações nas montanhas e as almas dos jovens nas praças" (p. 146).

Se analisarmos a prática profissional experimentada por autores como Mia Couto jornalista politicamente engajado, e Luís Cardoso, militante pela resistência do Povo Maubere, constatamos que suas escritas não são inocentes, e o fato de serem críticas da condição histórica colonial e do desmantelamento da utopia revolucionária no pós-colonial, já constitui uma tomada de posição em defesa dos direitos humanos, da sociedade civil e da liberdade de expressão. Ser escritor pode não ser uma missão, como descarta Mia Couto, mas existe uma simbologia significativa, na obra dos autores da diáspora lusófona, que nos 
permite dizer que a literatura constitui uma arma branca em favor da liberdade humana. Eles se tornam vozes que não se calam, não permitindo que a história caia no esquecimento.

\section{Referências}

ANDERSON, Benedict. "Imaginar Timor Leste". Tradução de Osvaldo Manuel Silvestre. Reproduzido de Ciberkiosk e de Arena Magazine, 4 de abr.-maio 1993.

BALAKRISHNAM, Gopal. (Org.) Um mapa da questão nacional. Introdução de Benedict Anderson. Tradução de Vera Ribeiro. Rio de Janeiro: Contraponto, 2000.

BHABHA, Homi. O local da cultura. Tradução de Myriam Ávila, Eliana Lourenço de Lima Reis, Gláucia Renate Gonçalves. Belo Horizonte: UFMG, 1998.

CAMPELO, Álvaro, Os refúgios da identidade. In: Gonçalves, Anónio Custódio. Actas do Colóquio África Subsariana: multiculturalismo, poder e etnicidade. Porto: Universidade do Porto, 2001. p. 129.

CARDOSO, Luís. Crônica de uma travessia. A época do Ai-Dik-Funam. Lisboa: Dom Quixote, 1997.

COUTO, Mia. Vinte e zinco. Lisboa: Caminho, 1999.

GUSDORF, Georges. Les écritures du moi. Paris: Odile Jacob, 1991.

HALL, Stuart. Da diáspora: identidades e mediações culturais. Tradução de Adelaine La Guardia Resende et al. Liv Sovik (Org.). Belo Horizonte: UFMG, 2003.

KI-ZERBO, Joseph. História da África Negra. Lisboa : Europa-América, 2000.

LEJEUNE, Phillipe. Le pacte autobiographique. Paris: Seuil, 1975.

LIMA, Fernando. Timor: da guerra do Pacífico à desanexação. Macau: Instituto Internacional de Macau, 2002.

MARCOS, Artur. Timor Timorense com suas línguas, literaturas, lusofonia. Lisboa: Colibri, 1995.

MATEUS, Dalila Cabrita. A luta pela independência: a formação das elites fundadoras da

FRELIMO, MPLA E PAIGC. Mira-Sintra: Inquérito, 1999.

MELO, João de. Autópsia de um mar de ruínas. Lisboa: Dom Quixote, 1997.

MONTEIRO, Renato; FARINHA, Luís. Guerra Colonial: Fotobiografia. Lisboa: Círculo de Leitores/Publicações Dom Quixote, [s.d]. 
SERRA, Carlos. Novos combates pela mentalidade sociológica. Maputo: Livraria Universitária da Universidade Eduardo Mondlane, 1997.

SILVA, Lurdes Marques. "Descolonização, nacionalismo e separatismo no Sudeste Asiático: os casos da Indonésia e Timor Leste”. França: Lusotopie, 2000. p. 359-374. 